\title{
Effect of Asanas on Selected Physical and Physiological Variables among Young Adult Women
}

\author{
K. Johnbosco \\ Assistant Professor, H. H. The Rajah's College Pudukkottai, Tamil Nadu, India \\ E-Mail: boscovks@gmail.com
}

\begin{abstract}
Today the awareness of maintaining good health has been on the high and people attend to physical exercise sessions even without knowing the actual physiological and spiritual values of yogic practices. To achieve this purpose, twenty four female students who are studying in Bharathidasan University affiliated college, Tiruchirappalli were selected as subjects at random and their age ranged between from 20-25 years Physical and physiological variable will be selected by reviewing and studying related literature in detail following criterion variables are selected for this. Physical variable flexibility and strength endurance physiological variable resting pulse rate breath holding time the pre and posttest control group design will be used for this study. To find out the significant difference on adjusted posttest among the groups, analysis of co-variance (ANCOVA) would use. There was significant improvement on flexibility, strength endurance physiological variable resting pulse rate breath holding time due to the effect of asanas training among young adult women. Keywords: Flexibility, Strength Endurance, Resting Pulse Rate, Breath Holding Time
\end{abstract}

\section{INTRODUCTION}

Now a day's majority of peoples are leading a mechanical life. They do not find time the bases for anill. Good mind and fine body are the foundations for the health of human life. When peoples do not take care of their body and mind they suffer from diseases. But in ancient time peoples had devoted much time for taking care of their body and mind. With the result they lived long and peaceful life. Today the awareness of maintaining good health has been on the high and people attend to physical exercise sessions even without knowing the actual physiological psychological and spiritual values of yogic practices. Asanas, pranayama and meditation help to maintain good health and to promote the efficiency of the vital internal organs of our body. Asanas are postures. According to patanjali, "any comfortable position that is steady is an asana". Asanas have a good influence on our body systems, particularly the respiratory and circulatory the nervous and the endocrine. The main purpose of the asana is to tone up our body systems and grant healthy life to people. It removes all sorts of diseases (N.C.Narayanan, 2002).

\section{A. Yoga}

The word yoga is derived from the Sanskrit root Yuj meaning to bind, join, attach and yoke, to direct and concentrate one's attention on, to use and apply. It also means union or communication. It is the true union of our will with the will of God. 'In thus means', says Mahadev Desai in his introduction to the Gita according to Gandhi, "the yoking of all the powers of body, mind and soul to God; it means the disciplining of the intellect, the mind, the emotions, the will, which that yoga pre-suppose; it means a poise of the soul which enables one to look at life in all its aspects greatly (Iyangar, 1985).

\section{METHODS OF MATERIALS}

To achieve this purpose, twenty four female students who are studying in Bharathidasan University affiliated college, Tiruchirappalli were selected as subjects at random and their age ranged between from 20-25 years Physical and physiological variable will be selected by reviewing and studying related literature in detail.

A feasible analysis to which these variables could be taken for the investigation is made in consultation with the supervisor who himself is an, keeping in mind the availability of the equipment, acceptability of the subjects and the suitable time that would be devoted for test as well as to keep the entire study integrated. Following criterion variables are selected for this. Physical variable flexibility and strength endurance physiological variable resting pulse rate breath holding time.

TABLE I TESTS SELECTION

\begin{tabular}{|l|c|}
\hline \multicolumn{1}{|c|}{ Variable } & Test \\
\hline Flexibility & Sit \& reach test \\
\hline Strength Endurance & Bent knee Sit - ups \\
\hline Resting pulse rate & Radial pulse rate \\
\hline Breath Holding time & Nostril clip method \\
\hline
\end{tabular}

\section{A. Statistical Procedure}

The pre and posttest control group design will be used for this study. To find out the significant difference on adjusted posttest among the groups, analysis of co-variance (ANCOVA) would use. In all case the criterion for statistical significance would set as 0.05 level of confidence. 
Table II ANalysis Of Covariance On FleXibility Of Asanas Training Group AND CONTROL Group

\begin{tabular}{|c|c|c|c|c|c|c|}
\hline \multicolumn{2}{|c|}{ Adjusted Post Test Means } & \multirow{2}{*}{ Source of Variance } & \multirow{2}{*}{ Sum of Square } & \multirow{2}{*}{ df } & \multirow{2}{*}{ Means Square } & \multirow{2}{*}{ F-ratio } \\
\hline Asanas Training Group & Control Group & & & & & \\
\hline \multirow{2}{*}{21.67} & \multirow{2}{*}{15.74} & Between & 32.30 & 1 & 32.30 & \multirow{2}{*}{$17.39 *$} \\
\hline & & With in & 39.10 & 21 & 1.86 & \\
\hline
\end{tabular}

*Significant at .05 level. The table value required for significance at 0.05 level with df 1 and 21 is 4.32 .

Table II shows that the adjusted post test means of asanas Training and control groups are 21.67 and 15.74 respectively. The obtained F-ratio value is 17.39 , which is greater than the table value 4.32 with df 1 and 21 required for significance at 0.05 level. Since the value of F-ratio is greater than the table value, it indicates that there is a significant difference among the adjusted post-test means of asanas Training and control groups.

Table II ANAlysis Of Covariance On STREngth Endurance Of Asanas Training Group AND Control Group

\begin{tabular}{|c|c|c|c|c|c|c|}
\hline \multicolumn{2}{|c|}{ Adjusted Post Test Means } & \multirow{2}{*}{ Source of Variance } & Sum of Square & df & Means Square & \multirow{2}{*}{ F-ratio } \\
\hline \multirow{2}{*}{ Asanas Training Group } & Control Group & & 33.93 & 1 & 33.93 & \multirow{2}{*}{$16.46^{*}$} \\
\cline { 2 - 6 } & \multirow{2}{*}{22.24} & Between & 43.30 & 21 & 2.06 & \\
\cline { 3 - 6 } & & With in & &
\end{tabular}

*Significant at 0.05 level confidence.The table value required for significance at 0.05 level with df 1 and 21 is 4.32

Table III shows that the adjusted post test means of asanas training and control group are 22.24 and 15.38 respectively. The obtained F-ratio value is 16.46 , which is greater than the table value 4.32 with df 1 and 21 required for significance at 0.05 level. Since the value of F-ratio is greater than the table value, it indicates that there is significant difference among the adjusted post-test means of asanas training and control group.

TABle Iv Analysis Of Covariance On Resting Heart Rate of Asanas Training Group AND Control Group

\begin{tabular}{|c|c|c|c|c|c|c|}
\hline \multicolumn{2}{|c|}{ Adjusted Post Test Means } & \multirow{2}{*}{ Source of Variance } & Sum of Square & df & Means Square & \multirow{2}{*}{ F-ratio } \\
\cline { 1 - 5 } Asanas Training Group & Control Group & & 49.61 & 1 & 49.61 & \multirow{2}{*}{$23.62 *$} \\
\cline { 3 - 6 } & \multirow{2}{*}{68.55} & Between & 44 & 21 & 2.10 & \\
\hline
\end{tabular}

*Significant at 0.05 level confidence.The table value required for significance at 0.05 level with df 1 and 21 is 4.32

Table IV shows that the adjusted post test means of asanas training and control group are 68.55 and 71.45 respectively. The obtained F-ratio value is 23.62 , which is greater than the table value 4.32 with df 1 and 21 required for significance at 0.05 level. Since the value of F-ratio is greater than the table value, it indicates that there is significant difference among the adjusted post-test means of asanas training and control group.

Table V Analysis Of Covariance On Breath Holding Time Of Asanas Training Group And Control Group

\begin{tabular}{|c|c|c|c|c|c|c|}
\hline \multicolumn{2}{|c|}{ Adjusted Post Test Means } & \multirow{2}{*}{ Source of Variance } & \multirow{2}{*}{ Sum of Square } & \multirow{2}{*}{ df } & \multirow{2}{*}{ Means Square } & \multirow{2}{*}{ F-ratio } \\
\hline Asanas Training Group & Control Group & & & & & \\
\hline \multirow{2}{*}{36.03} & \multirow{2}{*}{28.80} & Between & 119.33 & 1 & 119.33 & \multirow{2}{*}{$12.45^{*}$} \\
\hline & & With in & 201.24 & 21 & 9.58 & \\
\hline
\end{tabular}

*Significant at 0.05 level confidence. The table value required for significance at 0.05 level with df 1 and 21 is 4.32

Table $\mathrm{V}$ shows that the adjusted post test means of asanas training and control group are 36.03 and 28.80 respectively. The obtained F-ratio value is 12.45 , which is greater than the table value 4.32 with df 1 and 21 required for significance at 0.05 level. Since the value of F-ratio is greater than the table value, it indicates that there is significant difference among the adjusted post-test means of asanas training and control group

\section{DISCUSSION ON FINDINGS}

The result of study indicates that there was significant improvement on Flexibility, Strength Endurance, Resting
Heart Rate and Breath holding time due to the effect of asanas training among young adult women when compared to control group.

The result of study also indicates that there was significant difference among young adult women towards improving the selected physical and physiological variables such as Flexibility, Strength Endurance, Resting Heart Rate and Breath holding time than control group.

It is inferred from the literature and from the result of the present study. That systematically designed training 
develops dependent variables are very importance quilts for better performance in almost all sports and games. Hence it is concluded that systematically designed training may be given due recognition and implemented properly in the training programs of all the discipline in order to achieve maximum performance.

\section{CONCLUSION}

From the analysis of the data, the following conclusions were drawn.

1. There was significant improvement on flexibility due to the effect of asanas training among young adult women.

2. There was significant improvement on strength endurance due to the effect of asanas training among young adult women.

3. There was significant improvement on resting heart rate due to the effect of asanas training among young adult women.

4. There was significant improvement on breath holding time due to the effect of asanas training among young adult women.

5. There was significant difference among young adult women towards improving the selected physical and physiological variables such as Flexibility, Strength Endurance, resting heart rate and breath holding time than control group.

\section{REFERENCES}

[1] Akhtar, P., Yardi, S. \& Akhta, M. (2013, January). Effects of yoga on functional capacity and well-being. International Journal of Yoga, 6(1), 76-9. DOI: 10.4103/0973-6131.105952.

[2] Balaji, P. A., Varne, S. R., \& Ali, S. S. (2012, October). Physiological effects of yogic practices and transcendental meditation in health and disease.North American Journal of Medical Sciences, 4(10), 442-8. DOI: $10.4103 / 1947-2714.101980$.

[3] Chen, K. M., et al., (2007, February). Development and evaluation of a yoga exercise programme for older adults. J AdvNurs., 57(4), 43241.

[4] Clay, C. C., et al., (2005, August). The metabolic cost of hatha yoga. Journal of Strength and Conditioning Research, 19(3), 604-10.

[5] Cowen, V. S. (2010, January). Functional fitness improvements after a worksite-based yoga initiative. Journal of Bodywork and Movement Therapies, 14(1), 50-4. DOI: 10.1016/j.jbmt.2009.02.006.

[6] Damodaran, A., et al., (2002, May). Therapeutic potential of Yoga practices in modifying cardiovascular risk profile in middle aged men and women. Journal of Association Physicians India, 50(5), 631-632.

[7] Danucalov, M. A., et al., (2008, July). Cardiorespiratory and Metabolic Changes during Yoga Sessions: The Effects of Respiratory Exercises and Meditation Practices. Applied Psychophysiology and Biofeedback, 33(2), 77-81. 